\title{
Using a Sweating Manikin, Controlled by a Human Physiological Model, to Evaluate Liquid Cooling Garments
}

\author{
Robert Farrington \\ John Rugh \\ Desikan Bharathan \\ National Renewable Energy Laboratory \\ Heather Paul \\ Grant Bue \\ Luis Trevino \\ NASA Johnson Space Center
}

\begin{abstract}
An Advanced Automotive Manikin (ADAM) developed at the National Renewable Energy Laboratory (NREL) is used to evaluate NASA's liquid cooling garments (LCGs) used in advanced space suits for extravehicular applications, and launch and entry suits. The manikin is controlled by a finite-element physiological model of the human thermoregulatory system.

ADAM's thermal response to a baseline LCG was measured. The thermal sensation and comfort followed the expected trends as the LCG inlet fluid temperature was changed. The overall thermal comfort showed less variation than expected when testing points off the NASA comfort curve. These new thermal comfort tools permit detailed, repeatable measurements and evaluation of LCGs. Results can extend to other personal protective clothing, including HAZMAT suits, nuclear / biological / chemical protective suits, and fire protection suits.
\end{abstract}

\section{INTRODUCTION}

As shown in Figure 1, the LCG forms a part of the water loop system for the suited astronaut.
While Liquid Cooling and Ventilation Garment (LCVG) refers to the entire garment, and "LCG" only refers to the liquid cooling portion of the LCVG, at times these terms are interchangeable when referring to the cooling garment.

Although space is mostly a cold thermal environment, space suits have been conservatively designed like a thermos bottle to prevent both high heat losses (or heat leak), and high heat influx from the sun and infrared sources. This requires that the crewmember have cooling available at all times. Starting with the Gemini program through the International Space Station (ISS) program, an LCG has been used to cool the human body by removing heat from the skin directly to its water tubes of the LCG. Experience and analysis showed early on that gas cooling alone was insufficient (gas/water density ratio $\sim 1$ to 820 , gas/water heat capacity ratio $\sim 1$ to 4 ), and that an LCG was needed. Also, in the past, the principal heat removal method (heat rejection) has been via a sublimator, which removes heat by sublimating the water. A new heat rejection function for future exploration is the use of a radiator as a primary element to conserve the vented water. But in either case, the LCG is expected to remain the major heat acquisition element for removing heat from the crewmember, and 
improvements to the LCG are needed to reduce its weight by one-half for planetary missions, and to improve its performance.

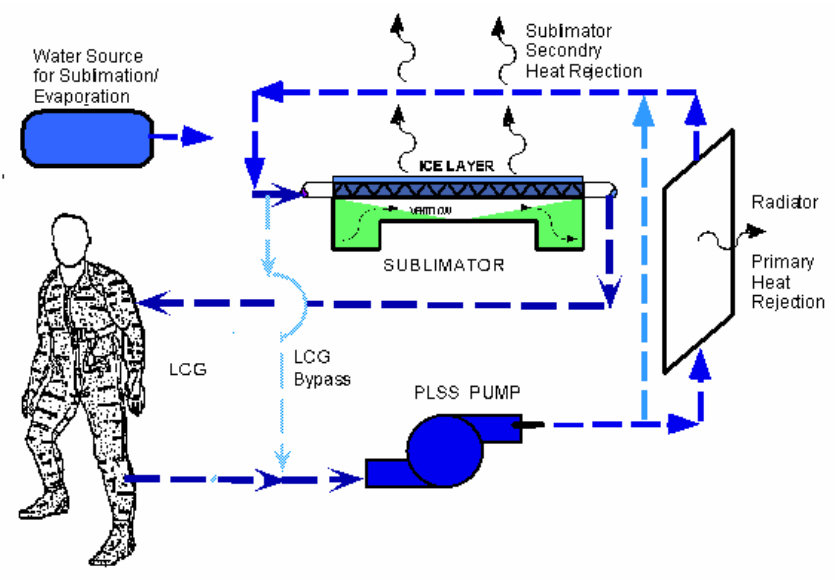

Figure 1. LCG and Water Loop System

\section{LIQUID COOLING GARMENT TEST HISTORY}

NASA's Johnson Space Center has been active in LCG development since it became clear during the first Gemini spacewalk that ventilation alone was insufficient for heat removal in most extravehicular activities (EVAs). The Apollo LCG consisted of a network of tubes covering the torso, thigh, calf, and uppers arms [1]. The Shuttle LCG differed slightly from the Apollo LCG. With cooling efficiencies similar to the Apollo LCG [3], the Shuttle LCG extended cooling to the forearms along with vent ducting, which became integral to the garment [2]. Another early effort to improve the LCG was directed toward automatic control concepts [4]. A human-LCG thermal math model was used to define a comfort curve providing a control target relationship for the control algorithm based on inlet temperature and metabolic rate [5].

The empirical relationship of cooling efficiency to flow rate and inlet temperature of the Shuttle LCG was refined with regression analysis from test data [6,7], and was used to improve modeling accuracy. A new comfort curve was developed using the revised model for further automatic control development $[8,9]$. These comfort curves were altered to reflect the comfort bias of crewpersons in subsequent testing with the Extravehicular Mobility Unit [10].
An exponential curve fit of the comfort curve used in this study is shown in Figure 2.

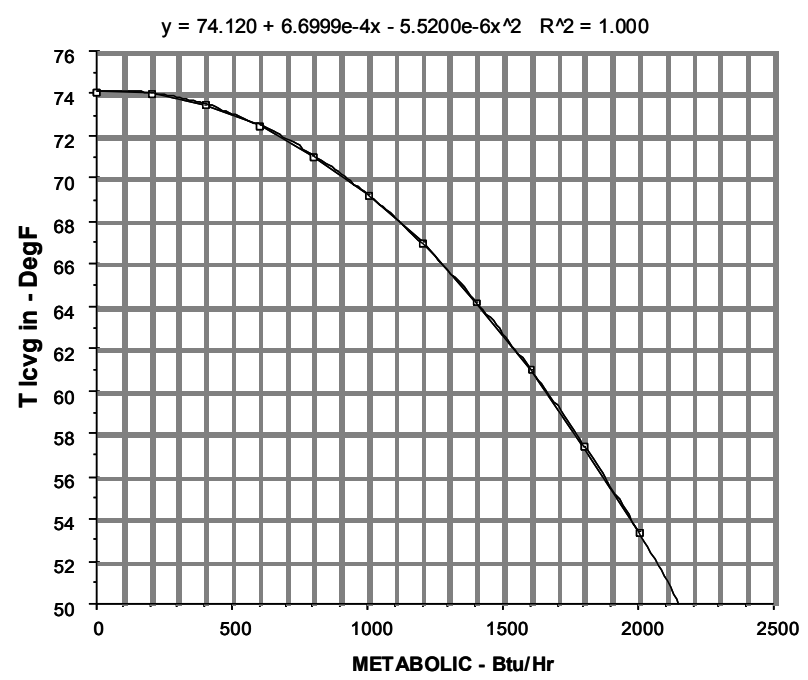

Figure 2. Auto Cooling Control Curve

Efforts to improve efficiency by supplying different coolant temperature to the torso, arms, and legs were deemed unsuccessful [11]. An important phenomenon has also been demonstrated-condensation accumulating on the LCG tubes during high heat load resulted in overcooling by subsequent evaporation during low heat load periods [12]. Selective tubing placement and other innovations have resulted in a garment that weighs $45 \%$ less than the Shuttle LCG [13], yet performs better [14].

\section{THERMAL COMFORT TOOLS}

The thermal comfort tools are composed of the manikin, the physiological control model, and the empirical thermal comfort model [15].

The Advanced Automotive Manikin, ADAM, has 120 separate heated and sweating segments (as shown in Figure 3) that provide uniform heating and sweating across the skin surface [16]. $\mathrm{He}$ is $175 \mathrm{~cm}$ tall and weighs approximately $61 \mathrm{~kg}$. Energy and water storage are contained in the manikin, which has wireless communication and control. The manikin's breathing, which can be used to exhale carbon dioxide and moisture for self-contained suits, was not needed for this evaluation. 


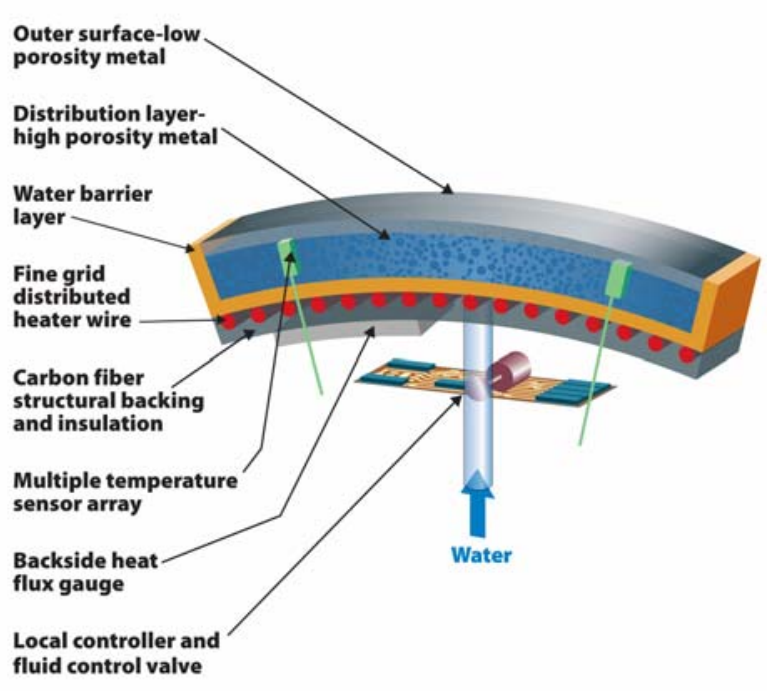

Figure 3. Diagram of manikin segment

A physiological finite element model approximates human thermoregulatory responses to external thermal stimuli and controls ADAM. The 40,000-element model, shown in Figure 4, predicts bone, muscle, fat, and skin temperatures as well as heat transfer through the circulatory system. Vasoconstriction and vasodilatation, as well as heat loss through breathing, are modeled [17, 18]. As a result, ADAM has human-like responses to thermal environments. For example, ADAM's skin temperatures decrease with distance from the torso. The numerical model predicts skin temperatures and sweating rates for the thermal environment and metabolic levels. These values are sent to ADAM who then changes the segment internal heat generation and sweating rates. ADAM then measures and sends the segment heat losses to the model for the next iteration.

The human thermal comfort empirical model is based on the results of 109 human subject tests under various non-uniform, transient thermal environments [19]. It determines how a person would feel thermally by determining local thermal sensations, which are used to predict local and global thermal comfort (thermal perception) [20].

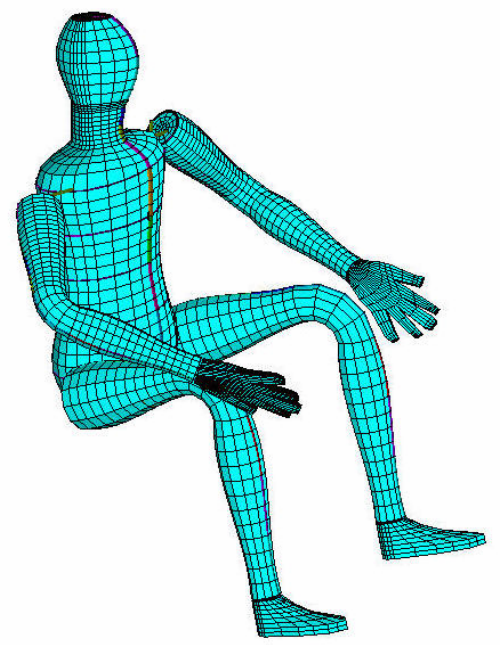

Figure 4. Finite element mesh for physiological model

These three systems work together, as shown in Figure 5 , to simulate human thermal sensation (hot versus cold) and human thermal comfort (comfortable versus uncomfortable) in transient, non-uniform, thermal environments.

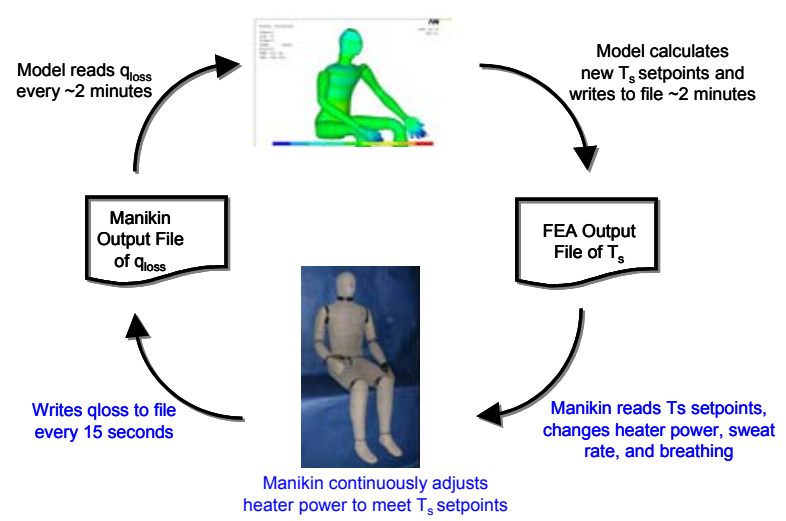

Figure 5. Interaction of manikin, physiological model, and empirical thermal comfort model

\section{TEST OBJECTIVES}

Although ADAM was designed for automotive testing, evaluating an LCG provided a good opportunity to explore other potential uses. The objectives for the LCG testing with ADAM were to:

1. Validate the ADAM manikin and model by comparing data from this test to physiological data generated from previous NASA testing 
2. Assess the manikin/model capability to test LCGs

3. Gather baseline data for the LCG

4. Test a cooling vest concept for performance comparison to LCG.

\section{TEST ARTICLES}

The LCVG is a conformal undergarment that covers the body from the neck to the wrists and ankles. Water flows through the LCVG flexible tubing to remove excess metabolic heat from the crewmember, and oxygen is vented from the helmet down to the hands and feet for further cooling. Figures 6 and 7 show the LCVG on ADAM.

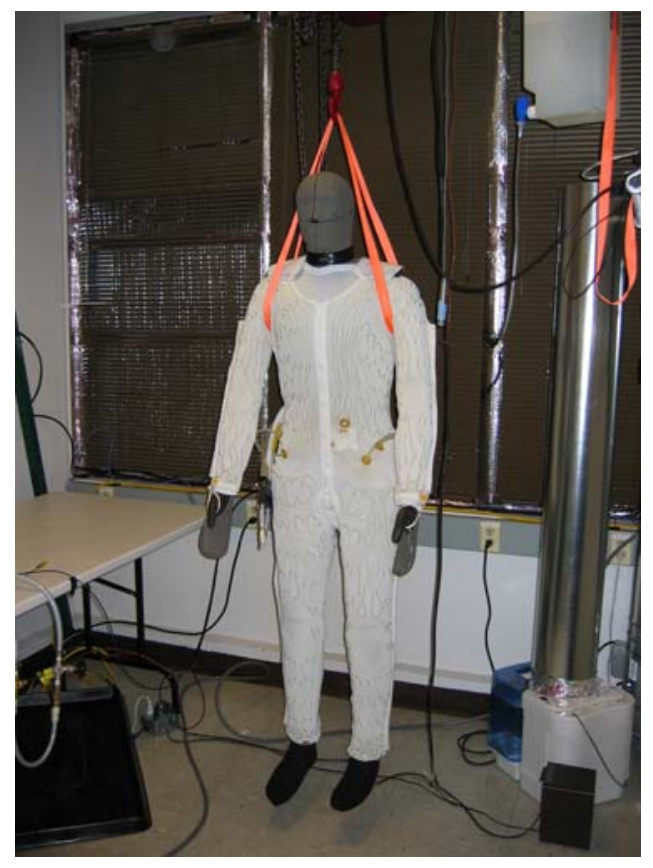

Figure 6. ADAM with LCG; front view

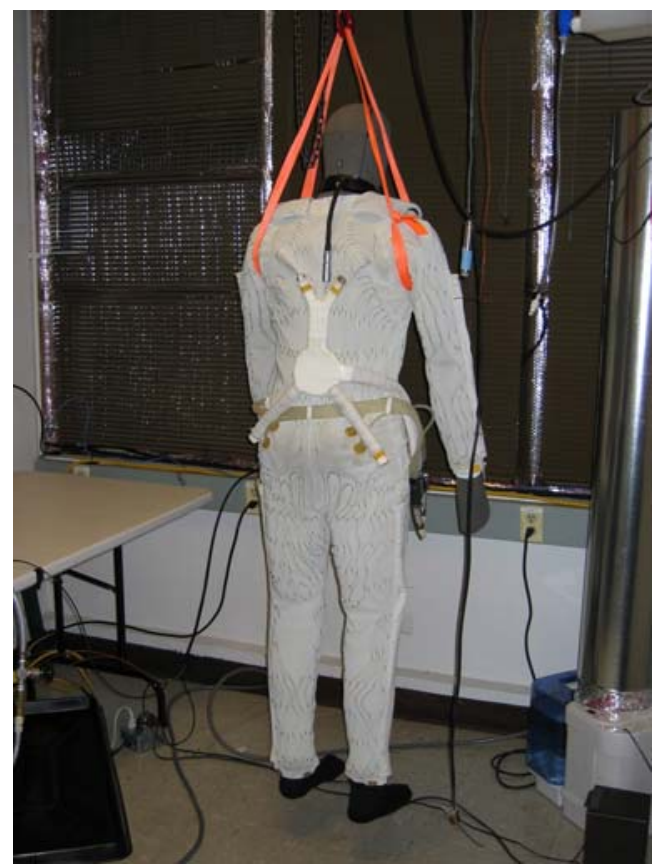

Figure 7. ADAM with LCG; back view

NASA purchased a Carbon $X$ Cool Shirt to evaluate the claim that the Carbon $X$ material has better overall thermal performance than standard materials. Figure 8 shows the Carbon $X$ Cool Shirt on ADAM.

According to Saferacer.com, the Carbon X Cool Shirt is manufactured with textiles from proprietary and inherently nonflammable fibers produced by Chapman Thermal Products. Carbon $X$ Textile T-shirts are heat and flame resistant, and wick moisture off the body with very minimal moisture retention in the fabric itself.

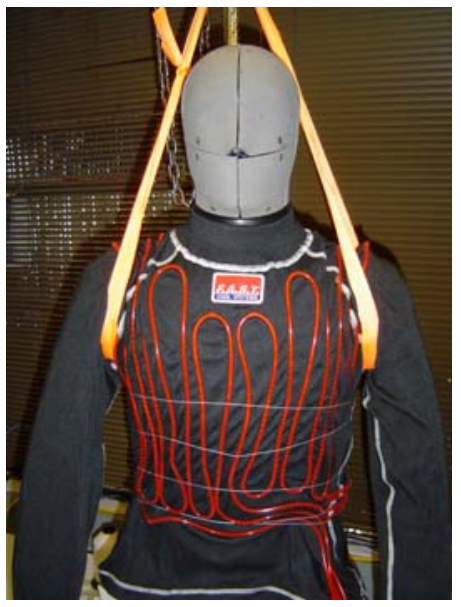

Figure 8. Carbon X Cool Shirt, front 


\section{TEST PROCEDURE}

The LCG tests with ADAM were conducted in the NREL Manikin Climate Control Chamber. The environmental controls consist of temperature and humidity. The chamber can maintain constant air temperatures from $17^{\circ} \mathrm{C}$ to $38^{\circ} \mathrm{C} \pm 0.5^{\circ} \mathrm{C}$ with a combination of electric heaters and chilled water heat exchangers. The relative humidity can be maintained between $25 \%$ and $50 \%$ with a portable humidifier.

Using Type $\mathrm{K}$ thermocouples, surface and air temperatures were measured at each wall as were the head, waist, and foot air temperatures at the manikin. The thermocouples were calibrated to $\pm 0.25^{\circ} \mathrm{C}$ using a Hart Scientific 7103 micro-bath. The data was logged using Labview software.

The room is approximately $2.5 \mathrm{~m}$ by $2.5 \mathrm{~m}$. Blowers in 2 corners of the room circulate air to promote mixing and a uniform air temperature. The maximum temperature difference between head and foot during the tests was $3^{\circ} \mathrm{C}$ during a warm test. The air velocity around ADAM was measured with a TSI hot wire velocity probe and was less than $0.1 \mathrm{~m} / \mathrm{s}$.

For the LCG test program, ADAM ran on building power and landline communication. The internal fluid reservoir was filled every morning prior to each test run to ensure an adequate supply of water needed for sweating. Within the chamber, there is a hoist to lift the manikin. This facilitates the dressing and undressing of ADAM as well as maintenance.

The liquid cooling garment is placed snuggly around the manikin to make intimate contact with the skin for all the flowing tests. Proper flow and temperature for the coolant to the LCG are established. The room air temperature is brought up to nominal $26^{\circ} \mathrm{C}$ for all cases. Room air humidity is continuously monitored and recorded. All segments of the manikin are brought up to a temperature of nominally $35^{\circ} \mathrm{C}$. Sweat rates for all the segments are set to the basal rate of nominally $25 \mathrm{~mL} / \mathrm{m}^{2} \mathrm{~h}$.

The physiological model is started by reading in the geometry and meshes in ANSYS, and the file containing detailed scripts of the transient model execution routine. First, initial conditions are imposed on the model as follows:
1) The metabolic heat generation rate for the model is set at nominally $96 \mathrm{~W}$, close to a basal rate.

2) All blood vessels are set to their corresponding basal diameters to cause the blood flow to attain basal values for the various body parts.

3) All segments are set to the basal sweat rate.

4) The heat fluxes for all segments are set to yield a nominal total skin surface loss of $87 \mathrm{~W}$.

5) The breath inlet temperature and humidity are provided to the physiological model using an auxiliary computer program to assess the heat carried away by breath.

6) The breath airflow rate is set at a basal rate of $6 \mathrm{~L} / \mathrm{m}$.

7) A uniform temperature of $35^{\circ} \mathrm{C}$ is imposed on all elements in the model.

The model carries out the first iteration using these initial conditions. This solution determines the body temperature distribution for all the nodes in the model.

Following each iteration of the model, a detailed set of scripts is executed to arrive at key body parameters and body thermal state. A detailed printout of the results is generated and stored as the record of the run.

All iterations following the first one are conducted in a transient mode. The time increment for the current step is set using the time it took to complete the last iteration. In this manner, we keep the model synchronized one step behind real time.

After each iteration, the core and mean skin temperatures are evaluated. They are used to calculate the effective sweat rates for all the body segments. These temperatures also govern the vasoconstriction and vasodilatation of all the blood vessels carrying blood to the skin, and determine the heat generation due to shivering rate. The model then outputs a file containing the predicted temperature and sweat rate for all the segments for use with ThermDAC, the program that controls the operation of the manikin. ThermDAC reads this file to continuously update the manikin segments and outputs a file that contains the skin heat fluxes for each segment. The physiological model updates the body boundary conditions with the updated measured heat 
fluxes from the manikin before continuing to the next iteration.

Typically, it takes between 1 to 2 hours for the model and the manikin to come to equilibrium with the surrounding; this occurs when the errors in the imposed heat generation and measured overall heat loss from the manikin are within about $\pm 3 \mathrm{~W}$.

The metabolic rate for the run can be changed at any time during the course of a run.

\section{TEST RESULTS}

The initial LCG cooling effectiveness tests were conducted at metabolic rates of $200 \mathrm{~W}$ and 350 $W$ over a duration of four hours. These parameters were set up to simulate the average planetary metabolic rate $(275 \mathrm{~W})$ for the estimated planetary EVA duration of 4 hours. For this evaluation, the liquid inlet temperature to the garment was adjusted to fall on the comfort curve shown in Figure 1. An additional set of tests were conducted at a constant metabolic rate of $275 \mathrm{~W}$, varying the coolant inlet temperature to fall $3.33^{\circ} \mathrm{C}$ higher and lower than the temperature dictated by the comfort calibration curve, with one test point on the comfort curve. All test results for the various cases are discussed below.

\section{CASE 1. $200 \mathrm{~W}$ WITH A COOLANT INLET TEMPERATURE OF $22.2^{\circ} \mathrm{C}\left(72^{\circ} \mathrm{F}\right)$}

Figure 9 shows the results of the transient tests conducted at two metabolic rates of $200 \mathrm{~W}$ and $350 \mathrm{~W}$. Traces of core temperature, effective metabolic rate, and total sweat rate are included in this figure. The core temperature plotted here is a volumetric average temperature of the brain tissue of the model. The abscissa shows the elapsed time in seconds from the start of the run.

At nearly $500 \mathrm{~s}$, a high metabolic rate of $200 \mathrm{~W}$ is imposed on the model. The model begins adapting to the new conditions with a monotonic rise in the core temperature. It begins at about $36.4^{\circ} \mathrm{C}$ and continuously rises to a steady-state value of nearly $36.7^{\circ} \mathrm{C}$. This rise occurs over a time period of about $8000 \mathrm{~s}$. The core temperature remains low causing a minimal amount of shivering in the body.

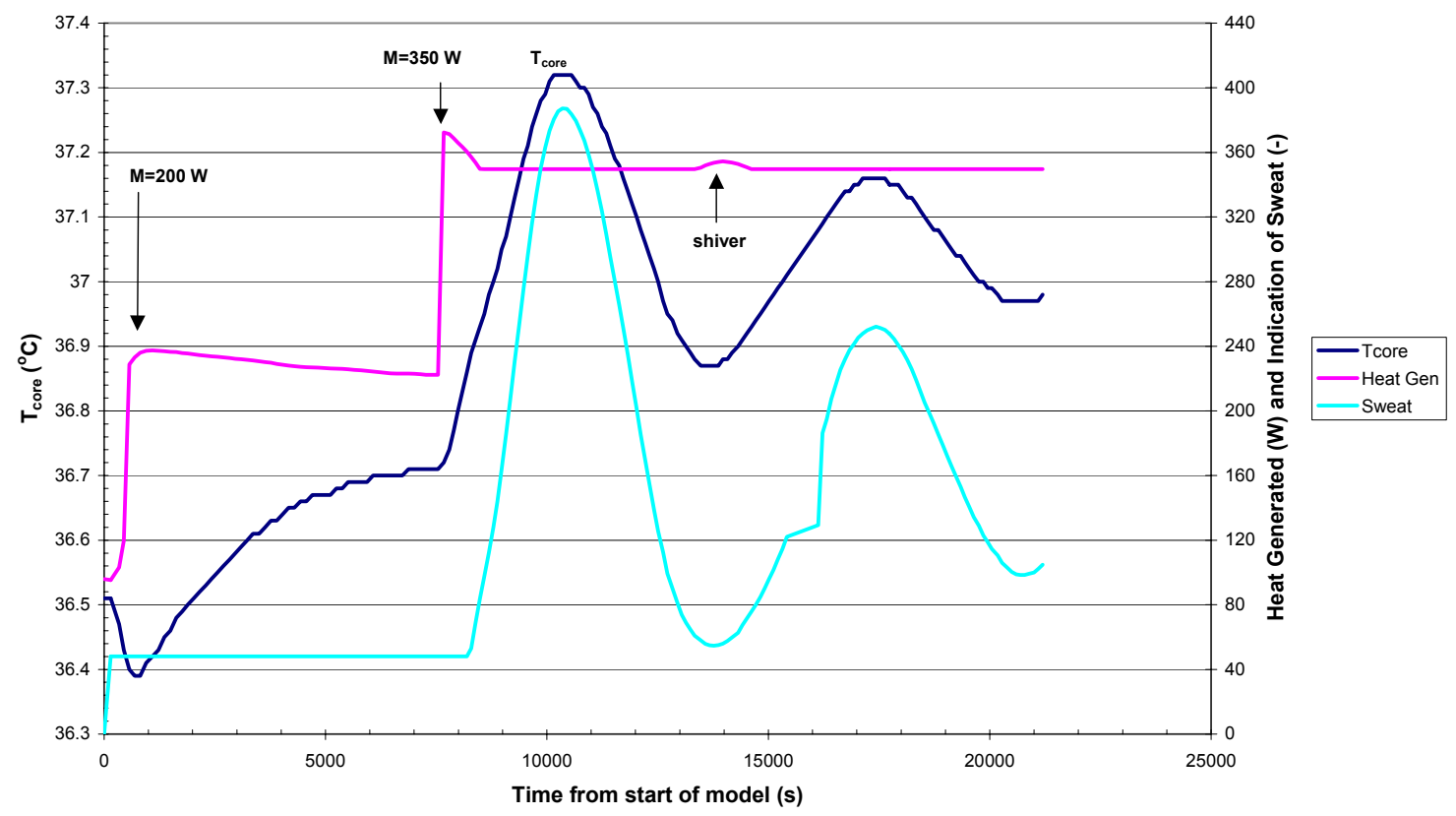

Figure 9. Time traces for core temperature, metabolic rate, and body sweat rate for the two metabolic rates of $200 \mathrm{~W}$ and $350 \mathrm{~W}$, in sequence for Cases (1) and (2) 
Since the core temperature is less than the sweat threshold temperature, the body's sweat rate does not increase and remains at its basal level. Table 1 summarizes further details of the model/manikin system. Temperatures for the various body parts and body's heat balance are indicated. Blood vessel constrictions are also summarized in Table 1.

Table 1. Summary of the steady-state results for a $200 \mathrm{~W}$ metabolic rate with LCG.

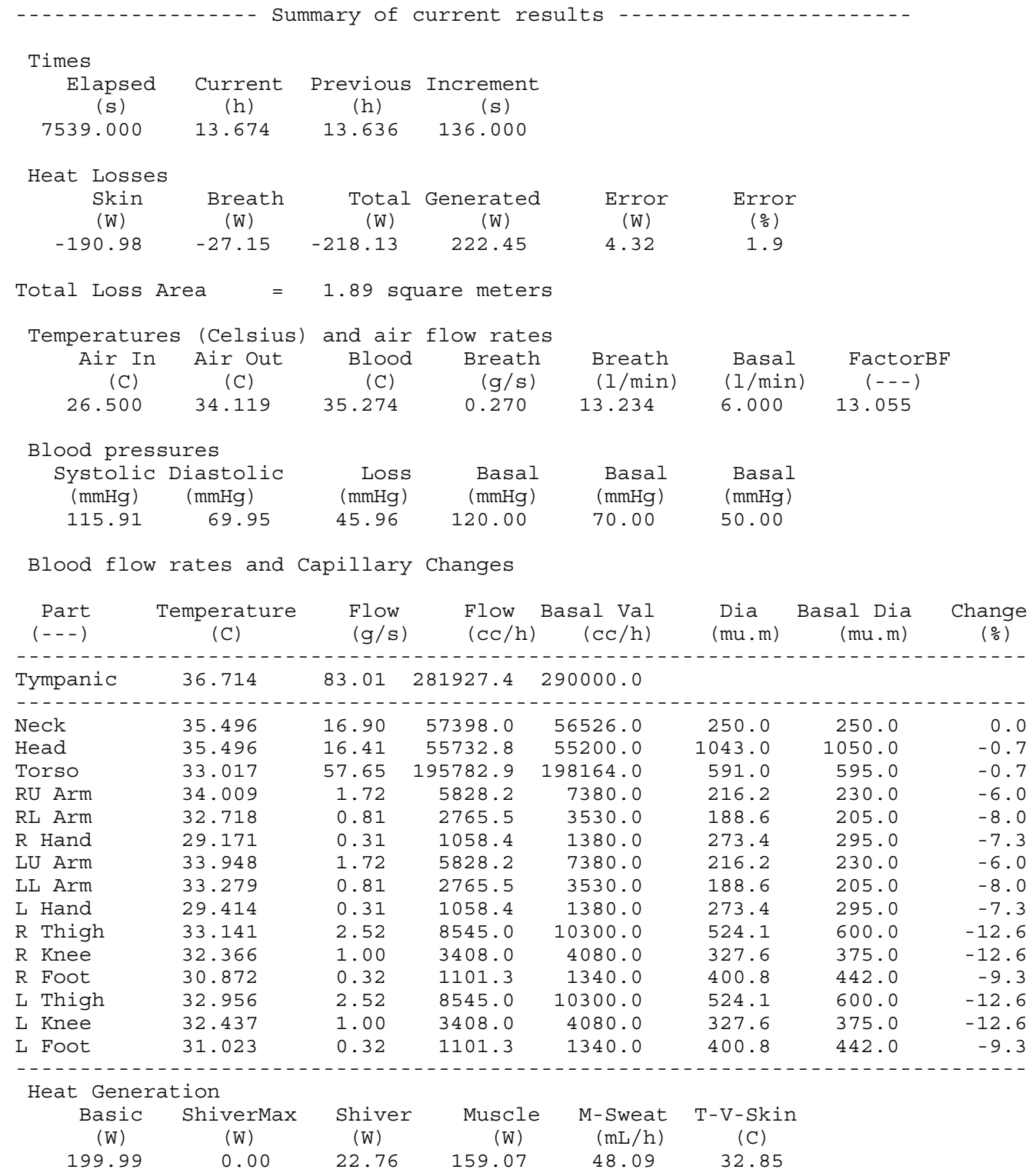


Figure 10 shows an infrared (IR) image of ADAM with liquid flowing through the LCG. Note the lack of cooling tubes around the knees and elbows to allow motion at the joints.

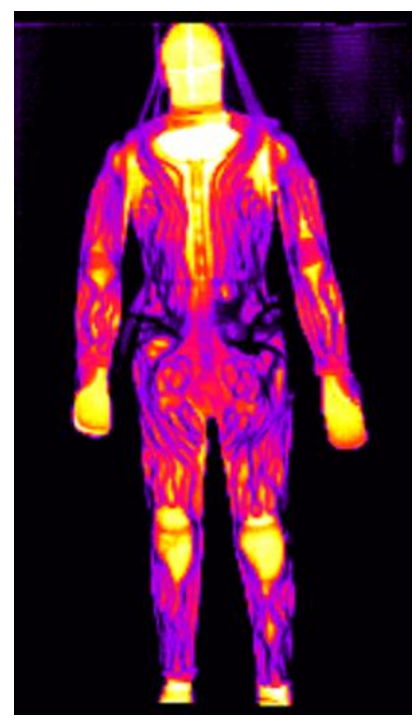

Figure 10. Infrared picture showing ADAM cooling after 3 minutes of flow

\section{CASE 2. 350 W WITH COOLANT INLET TEMPERATURE OF $19.5^{\circ} \mathrm{C}\left(68^{\circ} \mathrm{F}\right)$}

After the previous case, the traces in Figure 9 continue to indicate the ongoing results after the metabolic rate was increased to $350 \mathrm{~W}$ at the elapsed time of nearly $7700 \mathrm{~s}$. Rather interesting results follow.

The increase in metabolic rate causes the core temperature to begin to rise steeply. It overshoots the sweat threshold limit, continues to rise to a maximum of near $37.3^{\circ} \mathrm{C}$, and causes a 10-fold increase in sweating in a matter of about $3000 \mathrm{~s}$. All manikin segments and the garment become loaded with sweat. Accumulated sweat increases the rate of heat loss from the body and causes it to cool off rapidly. The physiological model then commands the sweat production halted. The manikin undergoes a period of "drying" for the next $3000 \mathrm{~s}$, by which time the core temperature reaches a minimum value of about $36.9^{\circ} \mathrm{C}$. It is worth noting that, on account of a too-low core temperature, a small amount of shivering can be observed.

This oscillation cycle in the core temperature is repeated once again, however, with a damped out rate and amplitude over the next $6000 \mathrm{~s}$. In this run, we were unable to continue testing to observe and arrive at the final steady-state set points.

Such temperature oscillations in the body core temperature are rarely reported in the literature. The authors have come across only one reference where the body and skin temperatures undershoot on account of sweat accumulation [21]. The LCG has a substantial moisture holding capacity. The manikin segments with their porous construction also possess such capacity. At this point, it is unclear whether the moisture accumulation in the clothing or the manikin segments is predominant, and which one of these results in the large temperature swings that we have observed thus far.

Figure 11 shows the variations in the overall body sensation and comfort. Both sensation and comfort are plotted on a scale of -4 to +4 . For sensation, positive values indicate that one is feeling hot, and negative values indicate that one is feeling cold. For comfort, the scale rising from negative to positive indicates being very uncomfortable $(-4)$ to very comfortable $(+4)$. We notice that for the LCG test at $200 \mathrm{~W}$, the resultant sensation is slightly warm and generally comfortable at the end of the test. Figure 12 shows the overall sensation at steady state for $200 \mathrm{~W}, 275 \mathrm{~W}$, and $350 \mathrm{~W}$ metabolic rates. Figure 13 shows the overall comfort. For the test at the higher metabolic rate of $350 \mathrm{~W}$, the final sensation is once again similar. These results indicate that the imposed coolant inlet temperature for the LCG is set correctly at values that are consistent with the set metabolic rate, which makes the person reasonably neutral thermally and generally comfortable. 


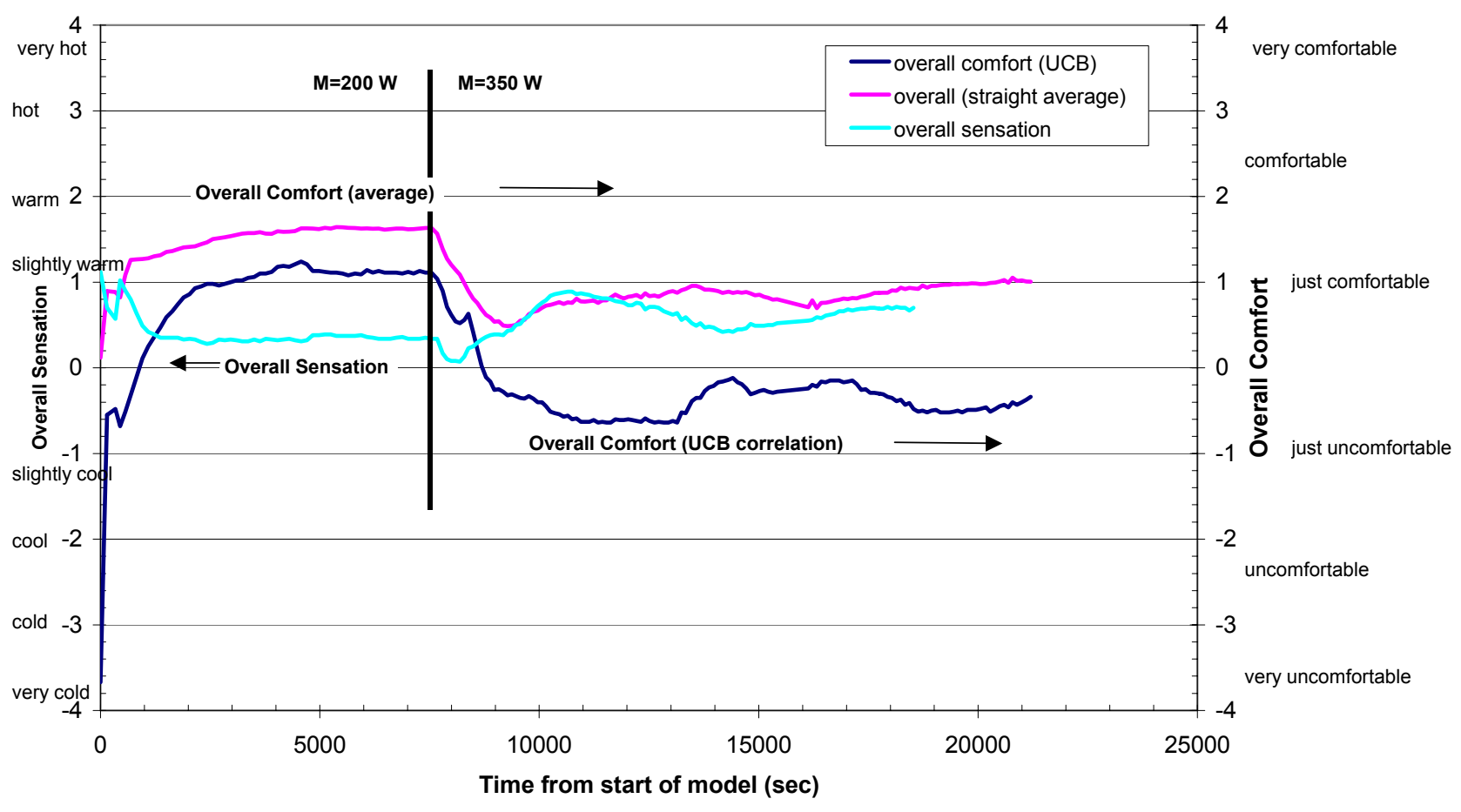

Figure 11. Transient traces for body sensation for the two metabolic rates of $200 \mathrm{~W}$ and $350 \mathrm{~W}$, in sequence for Cases (1) and (2)

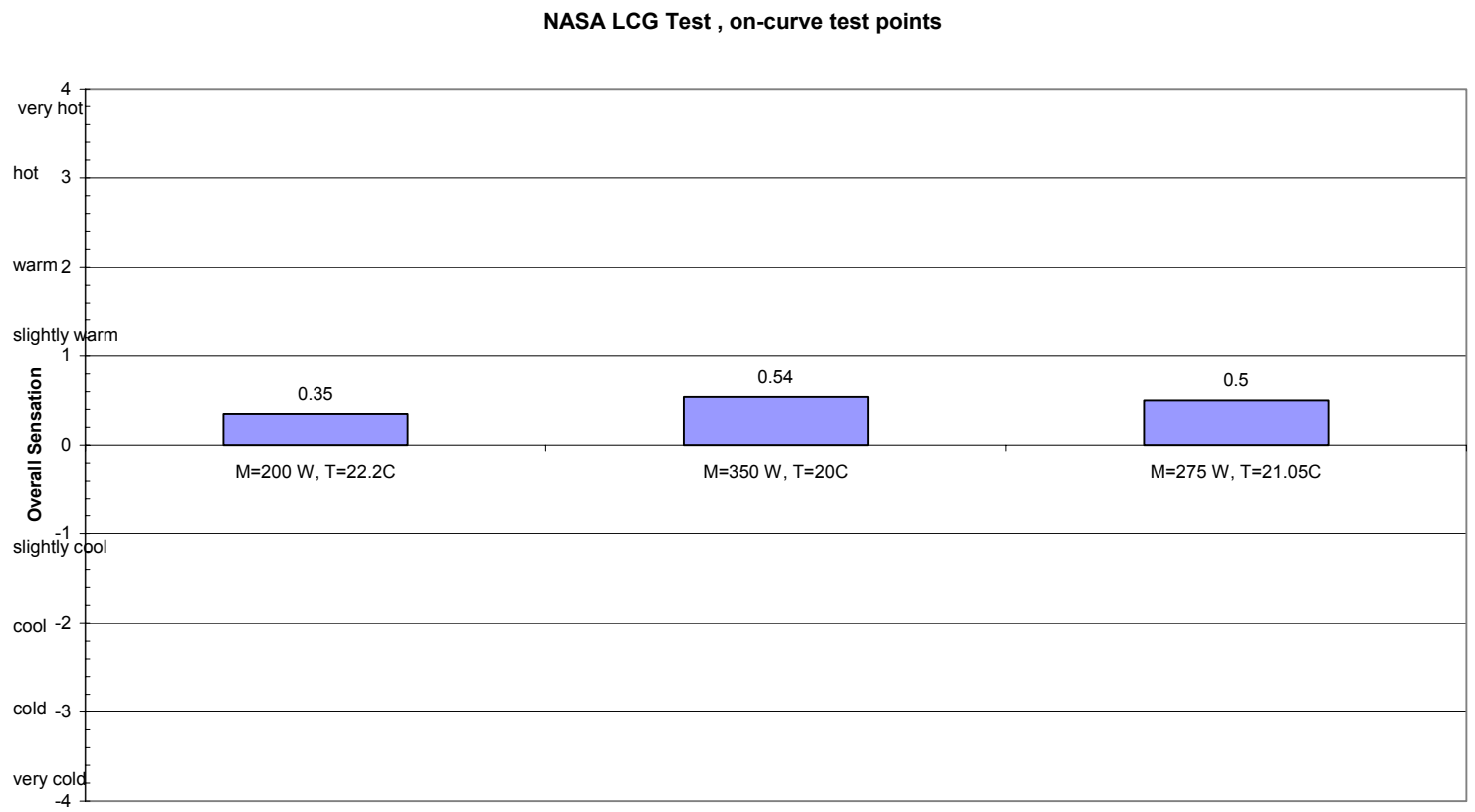

Figure 12. Overall sensation for three metabolic rates of $200 \mathrm{~W}, 275 \mathrm{~W}$, and $350 \mathrm{~W}$ 
NASA LCG Test, on-curve test points

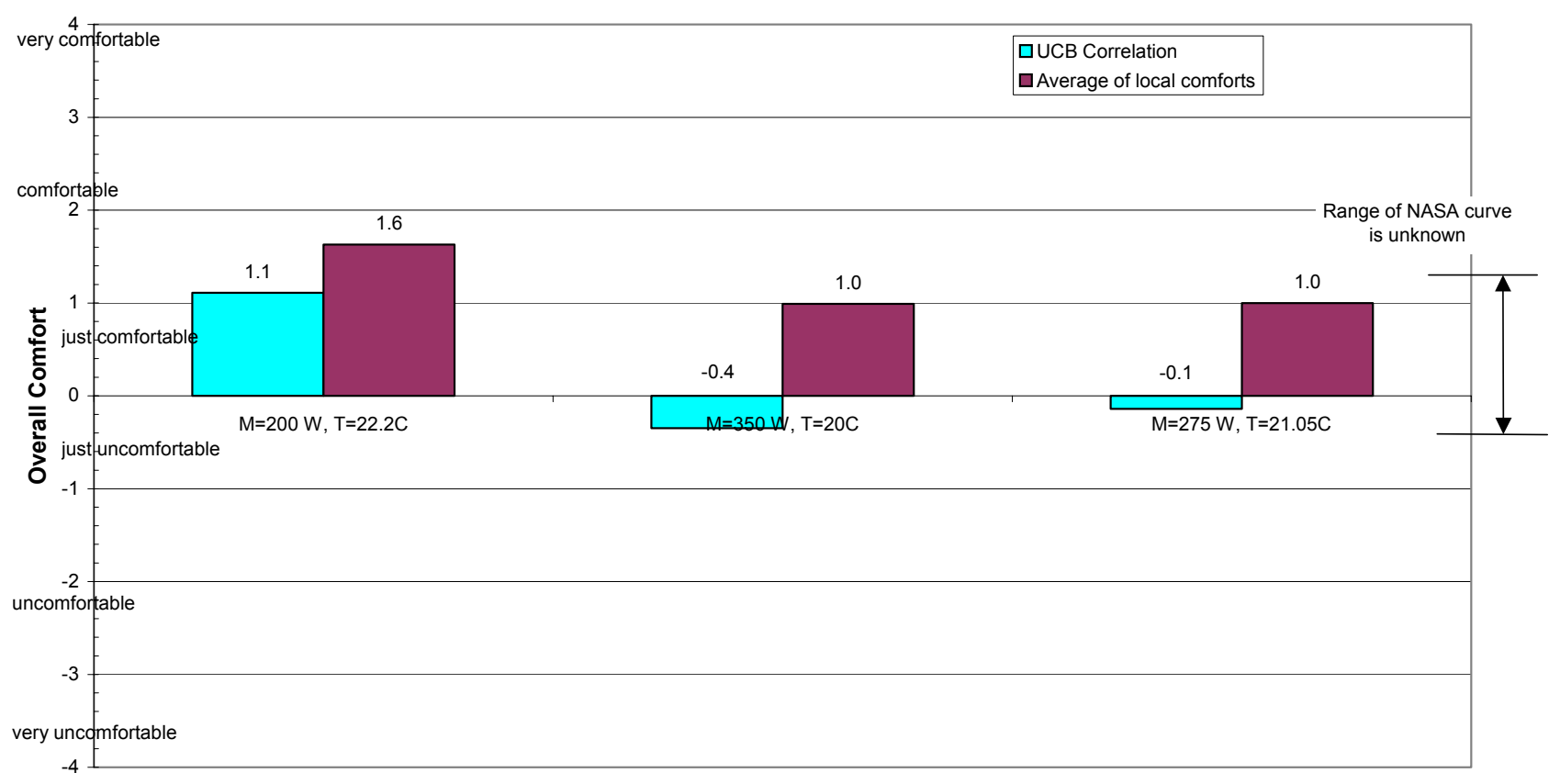

Figure 13. Overall Comfort for three metabolic rates of $200 \mathrm{~W}, 275 \mathrm{~W}$, and $350 \mathrm{~W}$

\section{CASE 3. $275 \mathrm{~W}$ WITH VARIED COOLANT INLET TEMPERATURES $\left(17.78^{\circ} \mathrm{C} \quad\left[64^{\circ} \mathrm{F}\right]\right.$, $19.5^{\circ} \mathrm{C}\left[70^{\circ} \mathrm{F}\right]$, and $\left.24.44^{\circ} \mathrm{C}\left[76^{\circ} \mathrm{F}\right]\right)$}

Transient tests were conducted at a metabolic rate of $275 \mathrm{~W}$ for three different coolant inlet temperatures. The temperatures were selected to fall below the specified value for comfort, on the curve, and above the comfort value in Figure 1. These temperatures are $17.78^{\circ} \mathrm{C}, 21.05^{\circ} \mathrm{C}$, and $24.44^{\circ} \mathrm{C}$. All other conditions for these tests were the same as described earlier.

Figure 14 shows the traces for core temperature, metabolic rate, and the body sweat rate under transient conditions for this test. The first test started from time zero and lasted up to an elapsed time of about $8000 \mathrm{~s}$. Steady-state conditions were reached for the first test at that time to yield a core temperature of nearly $36.9^{\circ} \mathrm{C}$. At this time, the coolant temperature was raised to the next level abruptly, and the model/manikin were allowed to find their equilibrium conditions. After an overshoot and undershoot, the core temperature reaches a steady-state value of $36.9^{\circ} \mathrm{C}$ at an elapsed time of $15000 \mathrm{~s}$. Following this, the coolant temperature was raised once again to be on the warm side. Oscillations followed on account of increasing core temperature and the resulting increased sweat rates. The run was stopped at the approximate midpoint of the oscillation at a core temperature of $37.0^{\circ} \mathrm{C}$. 


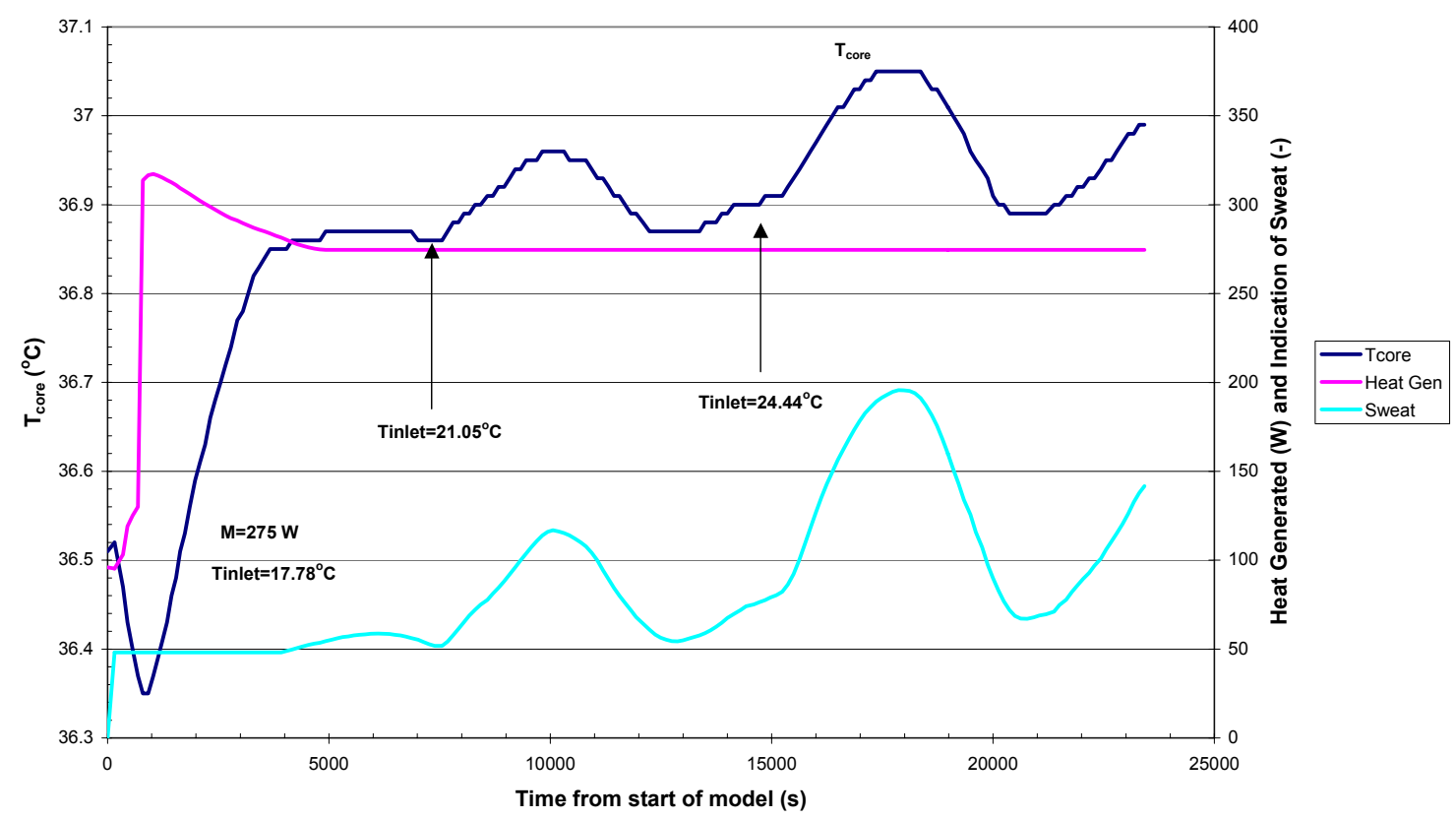

Figure 14. Transient traces for core temperature, metabolic rate, and body sweat rate for a metabolic rate of $275 \mathrm{~W}$, for three different coolant inlet temperatures

Figure 15 shows the overall sensation and comfort versus time for this test. For all three test conditions, the body's overall sensation remains slightly warm. As expected, the overall sensation grew warmer as the temperature of the coolant increased, as shown in Figure 16. The comfort differences between these three cases are not substantial (Figure 17).

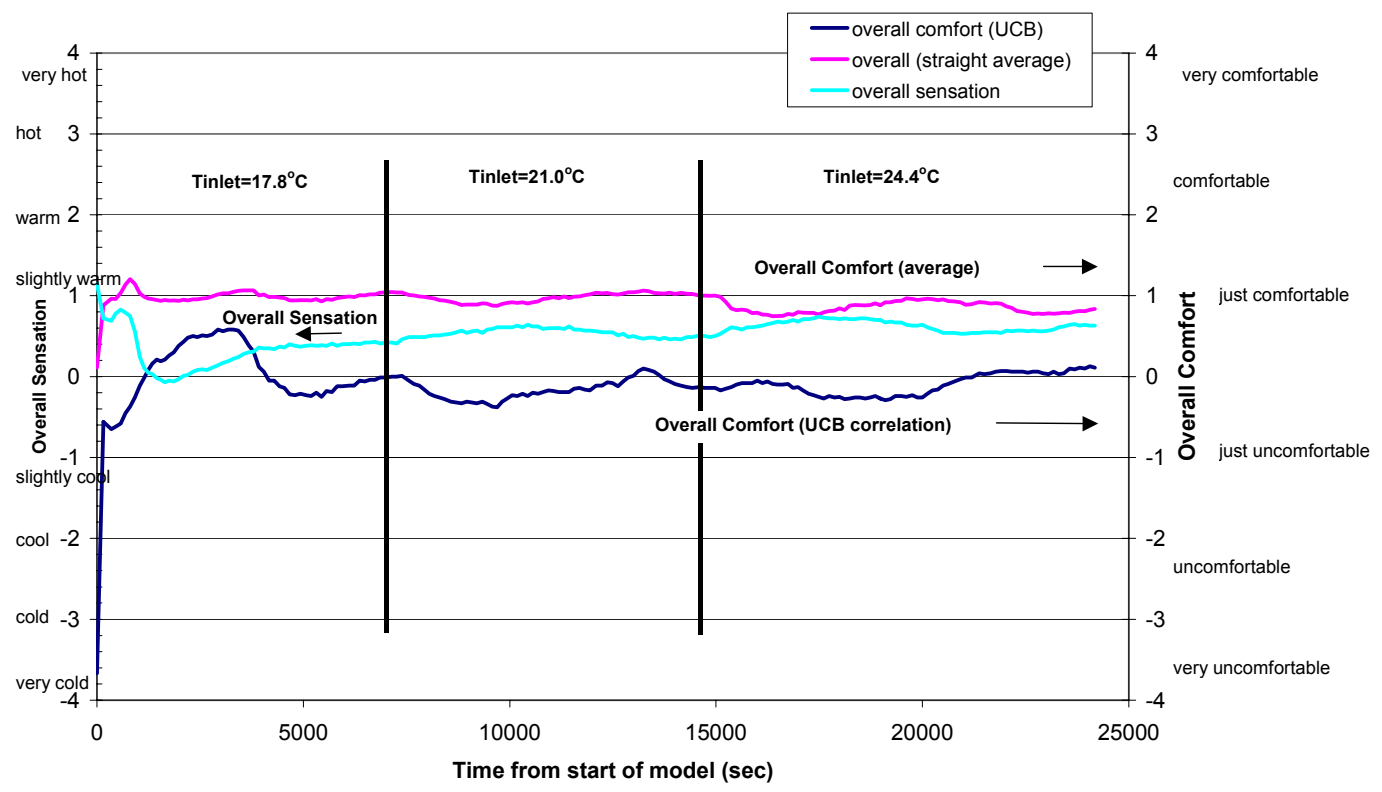

Figure 15. Transient traces for overall sensation and comfort for a metabolic rate of $275 \mathrm{~W}$, for three different coolant inlet temperatures 
NASA LCG Test, off-curve test points

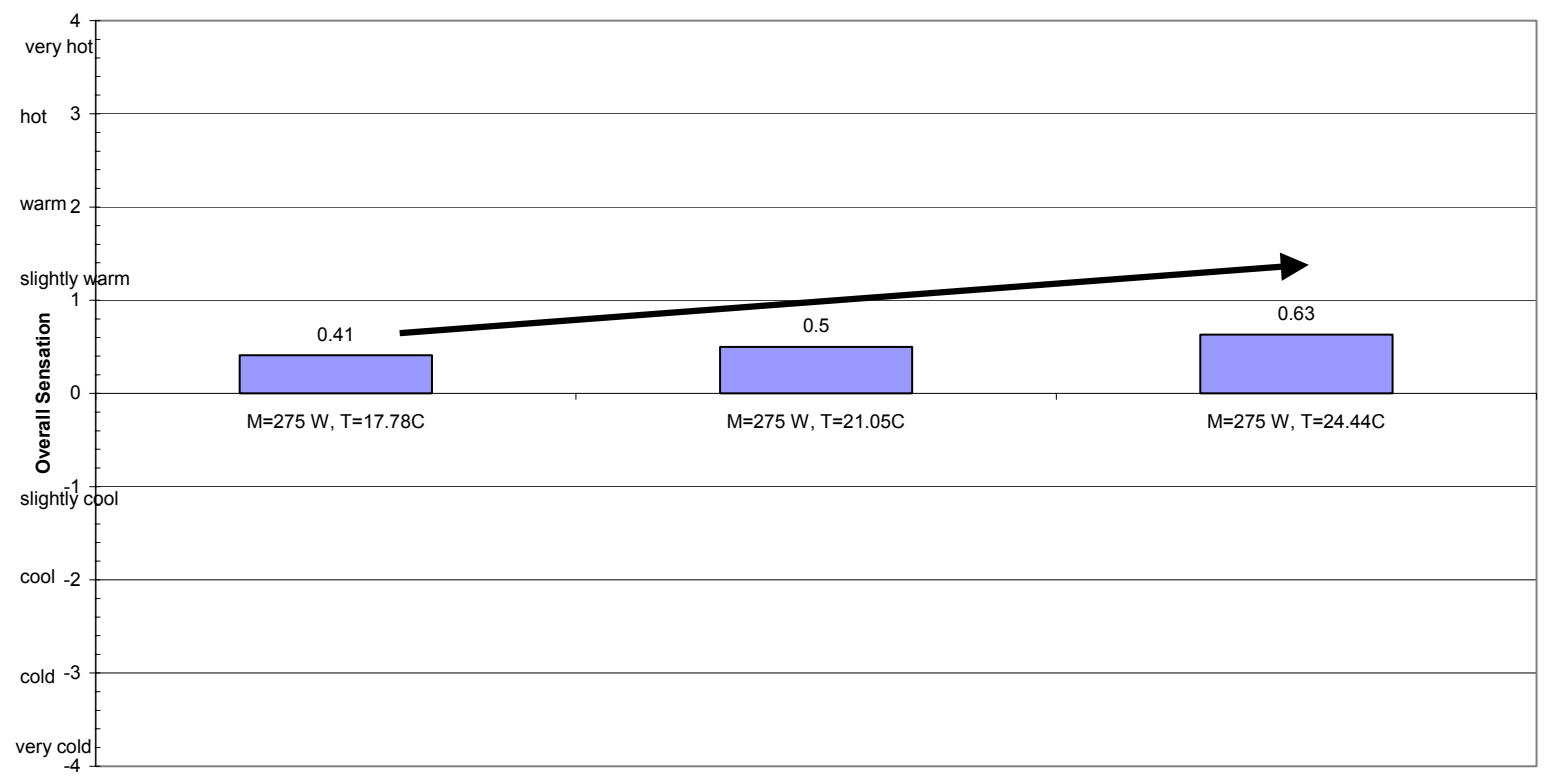

Figure 16. Overall sensation for a metabolic rate of $275 \mathrm{~W}$, for three different coolant inlet temperatures

NASA LCG Test, off-curve test points

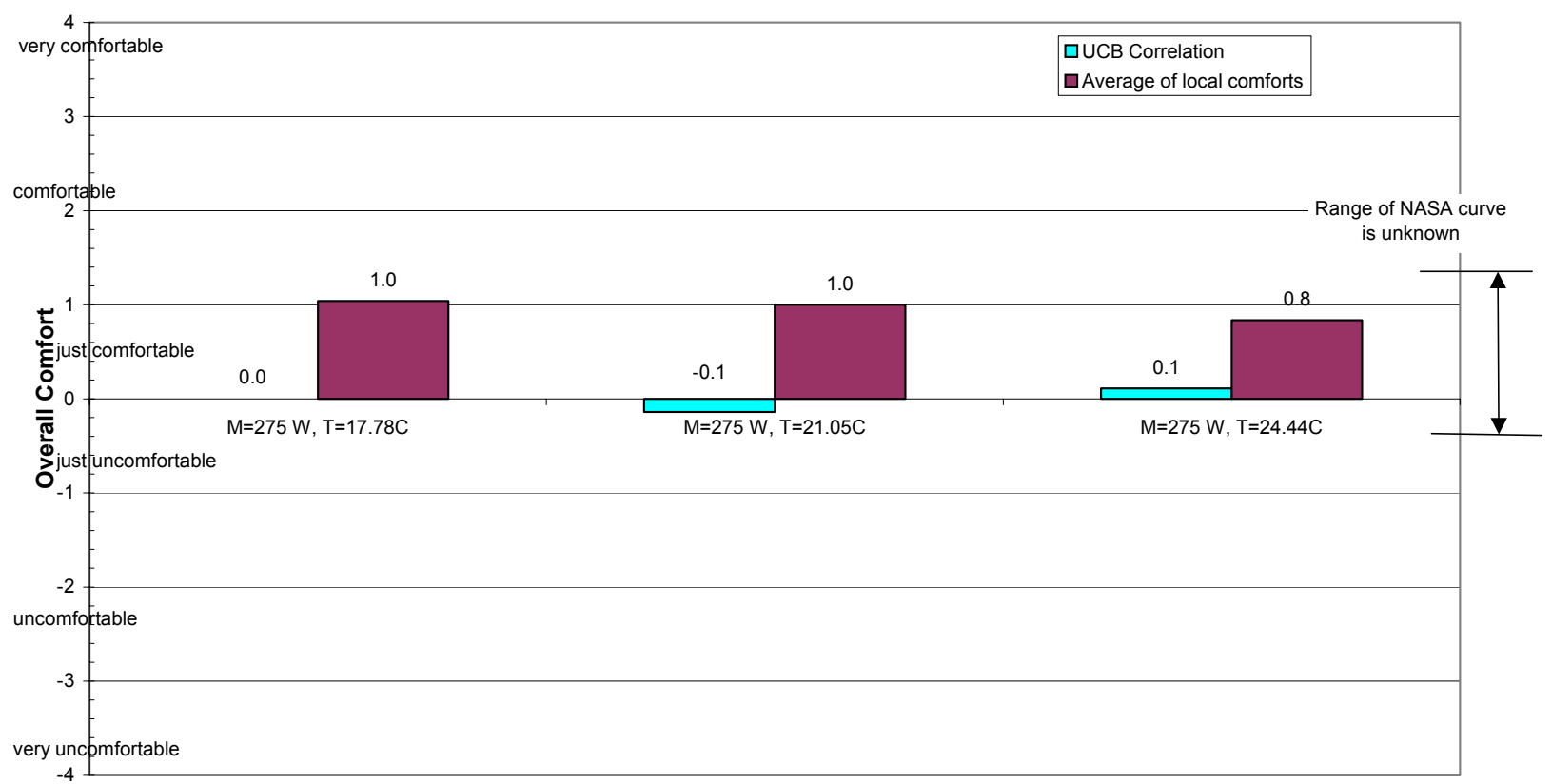

Figure 17. Overall Comfort for a metabolic rate of $275 \mathrm{~W}$, for three different coolant inlet temperatures 
CASE 4. TORSO TEST COMPARISON BETWEEN THE LCG AND CARBON X COOL SHIRT

In the next test, the thermal performance of the Carbon $X$ Cool Shirt was compared to the baseline performance of the LCG. Since the cooling tubes in the Carbon $X$ Cool Shirt were located only in the torso region, the arms and legs of the LCG were insulated with foam to reduce heat transfer to fluid in regions that were not heated, and the water flow rate was reduced to $106 \mathrm{lb} / \mathrm{hr}$, which is the estimated flow rate through the torso from the segmented NASA LCG test report [11]. Figure 18 shows the manikin wearing the LCG with the arms and legs insulated.

ADAM's skin temperatures were set to $35^{\circ} \mathrm{C}$, and the sweat rate was set to zero. The fluid inlet temperature was $22.1^{\circ} \mathrm{C}$, and the room air temperature was $26.2^{\circ} \mathrm{C}$. Test results indicate that the LCG performed better than the Carbon $X$ Cool Shirt because the LCG removed more heat from ADAM. An energy balance of the fluid shows that the Carbon $X$ Cool Shirt removed $43.1 \mathrm{~W}$ from the torso, while the LCG removed $56 \%$ more heat $(67.2 \mathrm{~W})$. The better thermal performance of the LCG was verified using data from ADAM. Summing the heat loss from the torso segments, ADAM measured $37.8 \mathrm{~W}$ of heat loss, which is $30 \%$ more than the $29.0 \mathrm{~W}$ removed by the Carbon $X$ shirt. We are looking into why the heat gain to the fluid does not correlate with the heat loss from the torso.

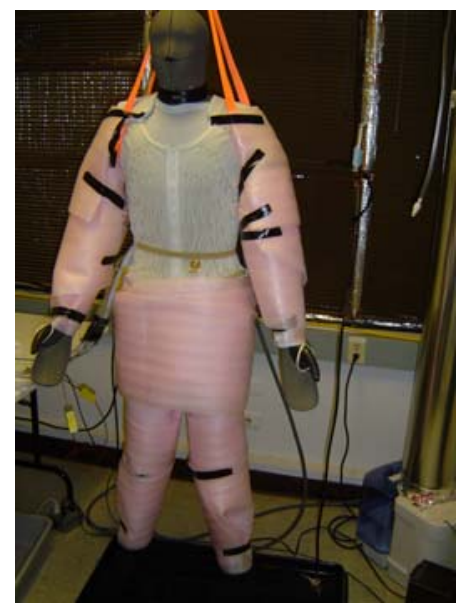

Figure 18. Manikin with LCG and foam insulation

\section{CONCLUSIONS}

This report presents results for the first of a series of tests using ADAM as a tool to evaluate LCGs for advanced space suits. Future tests will attempt to more accurately correlate ADAM to spacesuit LCG performance. But it must be emphasized that a simulation of the human thermoregulatory response will never be just like the actual human response. However, such a simulation, as provided by ADAM, can be useful initially as a relative comparison between garment performance profiles to save time in human testing. The goal is that test data from ADAM can be correlated to human test data to reflect a more accurate response and provide even more benefits for initial evaluations of LCG designs, with human testing providing the final certification of any flight LCG designs.

Objective 1 (validation) was not accomplished in this test, because physiological data from previous LCG testing was difficult to find, and/or test conditions were not able to be simulated correctly. Objectives 2 and 3 were met. ADAM has the ability to compare LCG options. Using ADAM, baseline data were collected for the LCG. Objective 4 was met. The Carbon $X$ Cool Shirt was tested and compared to the LCG.

Overall ADAM's response to comfort and sensation (temperature) followed the expected trends, although results between the on-curve and off-curve comfort testing showed less variation than expected. Knowing the margin on the comfort curve data will help determine if the test points of the off-curve testing were supposed to be in the "comfort range" as reported by ADAM. Comparing the data from the LCG and Carbon $X$ torso tests, the LCG removed more heat than the Carbon $X$ shirt. (Preliminary data shows that the LCG performed $30 \%-56 \%$ better than the Carbon $X$ shirt.) Although the current LCG contains more heat transfer area than the Carbon X LCG, only torso heat removal rates were compared to each other. However, due to some data discrepancies, the test data will be analyzed further to determine what if any benefits the Carbon $\mathrm{X}$ material can provide in future designs.

The high-spatial resolution of ADAM permits detailed analysis that can be used to determine the minimum number of segments a lower resolution manikin would need to evaluate LCGs 
or personal protective clothing. ADAM's sweating capability allows the impact of moisture evaporation and accumulation in personal protective suits and LCGs to be studied.

\section{FUTURE WORK}

Overall the test went very well with no major technical problems. Recommended future testing includes:

- Gathering data to validate ADAM/model and compare this data to physiological data generated from previous NASA testing. This can be achieved by simulating test conditions from a previous LCG test and comparing ADAM's response to the physiological data.

- Evaluating additional cooling garment concepts, including the Extra Cool Shirt developed by Chapman Thermal Products, and the ClimaTech Airvest. They'll be compared to the LCG and Carbon X Cool Shirt torso test results.

- Continuing to evaluate the results from these tests. NREL is investigating the model's comfort information to identify the best comfort correlation to use for these results; the Berkeley correlation (averages the two worst cases and the best) or taking a straight average (averages all segments) are options.

\section{ACKNOWLEDGMENTS}

The authors gratefully acknowledge the support of the U.S. Department of Energy (DOE) in developing, fabricating, and testing the thermal manikin and physiological model. DOE's Office of FreedomCAR and Vehicle Technologies (OFCVT) supported this work. The authors appreciate the support of Roland Gravel, DOE Program Manager; Terry Penney, NREL's OFCVT Technology Manager; and Barbara Goodman, Director of the Center for Transportation Technologies and Systems.

The authors gratefully acknowledge the assistance of Charles King in maintaining ADAM and conducting the tests.

\section{REFERENCES}

1. CSM/LM Spacecraft Operational Data Book, Vol. IV, EMU Data Book, Revision 2. (1971) NASA JSC document SNA-8-D-027 (IV) REV 2, Section 2.4, pp. 1-3.

2. NASA Extravehicular Mobility Unit (EMU) LSS/SSA Data Book, Rev K (2004), Hamilton Sunstrand, Section 3.8.

3. Kuznetz, L. H. (1977) Shuttle/Apollo Liquid Cooling Garment Cooling Efficiency Comparison, Quick Look Test Report, NASA JSC Crew and Thermal Systems Division.

4. Kuznetz, L. H. (1977) Automatic Control of Human Thermal Comfort with a LiquidCooled Garment, NASA TM-58205.

5. Kuznetz, L. H. (1976) Control of Thermal Balance by a Liquid Circulating Garment Based on a Mathematical Representation of the Human Thermoregulatory System, NASA TM X-58190.

6. Graves, G. (1978) Relationship of UA to LCVG coolant flow rate and inlet temperature, Hamilton Standard Document, H78-003-GG.

7. Smith, E. (1978) Establishing a Minimum UA for the LCG. Hamilton Standard Document, H78-005-ES.

8. Iovine, J. V. (1987) Liquid Cooling Garment Automatic Thermal Control Test Summary, Lockheed Document, LEMSCO-23523.

9. Bue, G. C. (1989) "Computer Program Documentation 41-Node Transient Metabolic Man Program," Lockheed Document, LESC-27578.

10. Dunaway, B. (1988) Automatic Liquid and Ventilation Cooling Garment Control Algorithm Final Test Report, NASA Document SSS87-221 (CTSD-SS-176).

11. Smith, G., and Pantermuehl, J. (1992) Segmented Liquid Cooled Garment Final Test Report, NASA Document JSC-25720 (CTSD-ADV-032).

12. Smith, G., Schneider, S., Keilich, M., and Conger, B. (1992) "Crew Member/Extravehicular Mobility Unit Thermal Interactions Affecting Cooling Preferences and Metabolic Water Removal," 25th International Conference on Environmental Systems, SAE 951637.

13. Koscheyev, V., Leon, G., and Trevino, R. (2002) "An Advanced Physiological Based Shortened Liquid Cooling/Warming Garment 
for Comfort Management in Routine and Emergency EVA," 32nd International Conference on Environmental Systems, SAE 2002-01-2413.

14. Koscheyev, V., Leon, G., A. Coca, Ferl, J. and Graziosi, D. (2004) "Comparison of Shortened and Standard Liquid Cooling Garments to Provide Physiological and Subjective Comfort," 34th International Conference on Environmental Systems, SAE 2004-01-2347.

15. Farrington, R.; Rugh, J.; Bharathan, D.; and Burke, R. (2004) "Use of a Thermal Manikin to Evaluate Human Thermoregulatory Responses in Transient, Non-Uniform, Thermal Environments," 4th International Conference on Environmental Systems, SAE 2004-01-2345, Colorado Springs, CO.

16. Burke, R.; Rugh, J.; and Farrington R. (2003) "ADAM - the Advanced Automotive Manikin," 5th International Meeting on Thermal Manikins and Modeling, Strasbourg, France.

17. Gordon, R. G.; Roemer, R. B.; and Horvath, S. M. (1976) "A Mathematical Model of the Human Temperature Regulatory System Transient Cold Exposure Response." IEEE Transactions on Biomedical Engineering 23, no. 6: 434-444.

18. Smith, C. E. (1991) A Transient, ThreeDimensional Model of the Human Thermal System. PhD Thesis, Kansas State University.

19. Zhang, H.; Huizenga, C.; and Arens E. (2003) "Thermal Sensation and Comfort in a Transient Non-Uniform Thermal Environment," 5th International Meeting on Thermal Manikins and Modeling,

20. Zhang, H.; (2004) Human Thermal Sensation and Comfort in Transient and Non-Uniform Thermal Environments, Ph.D. Thesis, U.C. Berkeley.

21. Takada, S.; Hokoi, S.; Kawakami, N.; and Kudo, M. (1999) "Effect of Sweat Accumulation in Clothing on Transient Thermophysiological Response of Human Body to the Environment," Proceedings of Building Simulation '99, Volume 1: 385-392.

\section{CONTACTS}

Desikan Bharathan, Ph.D., P.E., is a heat transfer and fluid dynamics expert. He has contributed to ocean thermal energy conversion systems, geothermal systems, building systems, and vehicle systems. He can be reached at: Desikan_Bharathan@nrel.gov.

Grant Bue, M.S.M.E., is lead for EVA worksite thermal analysis for the International Space Station at the NASA Johnson Space Center. He was involved in the design and testing of liquid cooling systems for the Shuttle Launch/Entry Suit. He is co-author of the computer program ASDA: Advanced Suit Design Analyzer. He can be reached at: grant.c.bue@nasa.gov.

Robert B. Farrington, Ph.D., P.E., manages the Advanced Vehicle Systems (AVS) Group for the National Renewable Energy Laboratory's (NREL) Center for Transportation Technologies and Systems. The AVS Group works on advanced power electronics, vehicle ancillary loads, heavy hybrid vehicles, vehicle modeling, and energy storage systems. He can be reached at:Rob_Farrington@nrel.gov.

Heather Paul is a part of the Advanced Extravehicular Activity Team at the NASA Johnson Space Center. She is the Ventilation Subsystem manager for the development of the next generation Portable Life Support Systems that will be used with the Lunar and Martian space suits. She also works with the Thermal Subsystem on evaluating cooling garment concepts. She can be reached at heather.I.paul@nasa.gov.

John Rugh, M.S.M.E., leads the vehicle ancillary loads reduction task at NREL. The objective of the project is to reduce fuel used for vehicle ancillary loads by reducing thermal loads, improving delivery efficiency, and increasing equipment efficiency including using engine waste heat to provide cabin cooling. He can be reached at: John_Rugh@nrel.gov.

Luis Trevino is a part of the Advanced Extravehicular Activity Team at the NASA Johnson Space Center. $\mathrm{He}$ is the Thermal Subsystem manager for the development of the next generation Portable Life Support Systems that will be used with the Lunar and Martian space suits. He can be reached at luis.trevino$1 @$ nasa.gov. 